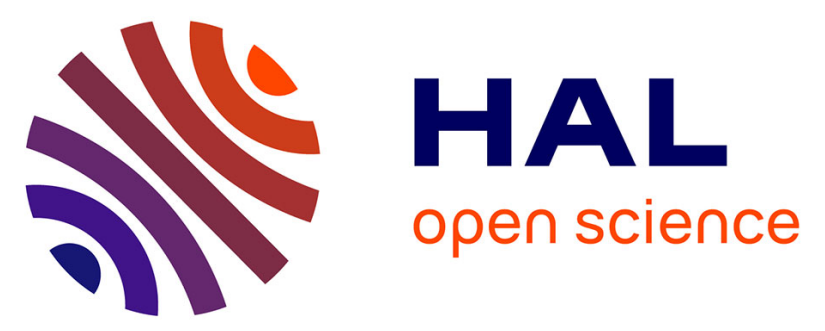

\title{
Prognostic impact of celiac lymph node involvement in patients after frontline treatment for advanced ovarian cancer
}

Martina Aida Angeles, Gwenaël Ferron, Bastien Cabarrou, Gisèle Balague, Carlos Martínez-Gómez, Laurence Gladieff, Christophe Pomel, Alejandra

Martinez

\section{To cite this version:}

Martina Aida Angeles, Gwenaël Ferron, Bastien Cabarrou, Gisèle Balague, Carlos MartínezGómez, et al.. Prognostic impact of celiac lymph node involvement in patients after frontline treatment for advanced ovarian cancer. EJSO - European Journal of Surgical Oncology, 2019, 10.1016/j.ejso.2019.02.018 . hal-02090344

\section{HAL Id: hal-02090344 \\ https://hal.science/hal-02090344}

Submitted on 25 Oct 2021

HAL is a multi-disciplinary open access archive for the deposit and dissemination of scientific research documents, whether they are published or not. The documents may come from teaching and research institutions in France or abroad, or from public or private research centers.
L'archive ouverte pluridisciplinaire HAL, est destinée au dépôt et à la diffusion de documents scientifiques de niveau recherche, publiés ou non, émanant des établissements d'enseignement et de recherche français ou étrangers, des laboratoires publics ou privés.

\section{(ㄷ)(1) $\$$}

Distributed under a Creative Commons Attribution - NonCommerciall 4.0 International 
1 Title: Prognostic Impact of Celiac Lymph Node Involvement in patients after Frontline

2 Treatment for Advanced Ovarian Cancer

3

4 Authors: Martina Aida Angeles ${ }^{1}, \mathrm{MD}$; Gwénaël Ferron ${ }^{1,2}, \mathrm{MD}, \mathrm{PhD}$; Bastien Cabarrou ${ }^{3}$,

$5 \mathrm{PhD}$; Gisèle Balague ${ }^{4}, \mathrm{MD}$; Carlos Martínez-Gómez ${ }^{1,5}, \mathrm{MD}$; Laurence Gladieff ${ }^{6}, \mathrm{MD}$;

6 Christophe Pomel $^{7}, \mathrm{MD}, \mathrm{PhD}$; Alejandra Martinez ${ }^{1,5}, \mathrm{MD}, \mathrm{PhD}$.

7

8

Affiliations:

${ }^{1}$ Department of Surgical Oncology, Institut Claudius Regaud - Institut Universitaire du Cancer de Toulouse (IUCT) - Oncopole, Toulouse, France.

${ }^{2}$ INSERM CRCT 19, Toulouse, France.

${ }^{3}$ Biostatistics Unit, Institut Claudius Regaud - Institut Universitaire du Cancer de Toulouse (IUCT) - Oncopole, Toulouse, France.

${ }^{4}$ Department of Radiology, Institut Claudius Regaud - Institut Universitaire du Cancer de Toulouse (IUCT) - Oncopole, Toulouse, France.

${ }^{5}$ INSERM CRCT 1, Toulouse, France.

${ }^{6}$ Department of Medical Oncology, Institut Claudius Regaud - Institut Universitaire du Cancer de Toulouse (IUCT) - Oncopole, Toulouse, France.

${ }^{7}$ Department of Surgical Oncology, CRLCC Jean Perrin, Clermont-Ferrand, France.

\section{Corresponding author:}

Alejandra Martinez, MD, PhD

Institut Claudius Regaud - Institut Universitaire du Cancer de Toulouse (IUCT) - Oncopole 1 avenue Irène Joliot-Curie 31059 TOULOUSE Cedex 9 
Martinez.Alejandra@iuct-oncopole.fr

Conflict of Interest: none.

\section{Acknowledgements:}

Martina Aida Angeles acknowledges the grant support from "la Caixa" Foundation, Barcelona (Spain).

Carlos Martínez-Gómez acknowledges the grant support from Alfonso Martín Escudero

Foundation, Madrid (Spain).

Martina Aida Angeles: https://orcid.org/0000-0003-4401-3084

Gwénaël Ferron: https://orcid.org/0000-0002-1003-9916

Bastien Cabarrou: https://orcid.org/0000-0003-1477-6013

Gisèle Balagué: https://orcid.org/0000-0002-3572-3378

Carlos Martínez-Gómez: https://orcid.org/0000-0002-9652-7880

Laurence Gladieff: https://orcid.org/0000-0002-6980-9719

42

Christophe Pomel: https://orcid.org/0000-0003-3903-7321

Alejandra Martinez: https://orcid.org/0000-0002-7633-3536

44 


\section{Abstract}

\section{Introduction}

Completeness of cytoreduction is the most important prognostic factor in patients with advanced ovarian cancer (OC). Extensive upper abdominal surgery has allowed to increase the rate complete cytoreduction and the feasibility of resection of celiac lymph nodes (CLN) and porta hepatis disease in these patients has been demonstrated. The aim of our study was to assess the prognostic impact of CLN involvement in patients with primary advanced OC undergoing a complete cytoreductive surgery (CRS).

\section{Material and methods}

We designed a retrospective unicentric study. We reviewed data from patients who underwent CLN resection with or without porta hepatis disease resection, within upfront or interval complete CRS in the frontline treatment of advanced epithelial OC between January 2008 and December 2015. Patients were classified in two groups according to CLN status. Univariate and multivariate analyses were conducted. Survival rates were estimated using Kaplan-Meier method.

\section{Results}

Forty-three patients were included and positive CLN were found in $39.5 \%$ of them. The median disease-free survival in the group of patients with positive and negative CLN were 11.3 months and 25.8 months, respectively. In multivariable analysis, both CLN involvement and high peritoneal cancer index were independently associated with decreased disease-free survival. Computed tomography re-reading by an expert radiologist has good sensitivity for detection of positive CLN.

\section{Conclusion}

CLN involvement and high preoperative tumor burden are independently associated with decreased survival after complete cytoreduction for OC. CLN involvement is a marker of 
70 diffuse disease and an independent risk factor for early recurrent disease.

71

72 Keywords: celiac lymph node status, porta hepatis disease, advanced epithelial ovarian

73 cancer, peritoneal ovarian carcinomatosis, upper abdominal procedures. 
Text

\section{INTRODUCTION}

Completeness of cytoreduction has demonstrated to have a more significant influence on survival of patients with advanced ovarian cancer (OC) than the extent of the metastatic disease present before the surgery[1]. In the last decades, there has been an evolution in the surgical approach of advanced OC. The incorporation of extensive upper abdominal procedures (UAP) has allowed to almost double the rate of optimal cytoreduction[2,3]. Celiac lymph nodes (CLN) and porta hepatis (PH) are one of the disease sites, which can hinder a complete cytoreduction. In order to improve complete cytoreduction rates, we demonstrated the feasibility with an acceptable morbidity of the resection of CLN and PH disease in patients with advanced or recurrent OC[4]. Moreover, we showed that disease in CLN in primary or recurrent $\mathrm{OC}$ was a marker of disease severity and that these patients had a worse oncologic outcome[5].

The aim of our study was to evaluate the prognostic impact of CLN involvement in a homogeneous cohort of patients who underwent a complete cytoreductive surgery (CRS) for a primary diagnosis of advanced OC (FIGO stage IIIC-IV).

\section{MATERIALS AND METHODS}

\subsection{Patients and study design}

A computer-generated search of our institution patient database was carried out to retrospectively identify all patients who underwent CLN resection with or without PH disease resection, within upfront or interval complete CRS in the frontline treatment of advanced (FIGO stage IIIC-IV) epithelial ovarian, fallopian or primary peritoneal cancer between 
January 2008 and December 2015 at the French Comprehensive Cancer Center, Institut Claudius Regaud - Institut Universitaire du Cancer de Toulouse, France. Institutional Review Board approval was obtained from our center.

\subsection{Preoperative assessment, surgery principles and chemotherapy treatment}

All the patients underwent a preoperative imaging study including a computed tomography (CT) of the chest, abdomen and pelvis. In selected cases of extra-abdominal disease suspicion, a positron emission tomography was performed.

All the surgical procedures were performed by two experienced oncological surgeons. The surgical technique of CRS was performed following Surgarbaker principles of peritonectomy[6] and the CLN and PH disease resection was carried out as we previously described[4]. The extent and distribution of the disease throughout the 13 abdominopelvic regions were evaluated with the peritoneal cancer index (PCI). The main goal of the surgery was to obtain a complete cytoreduction, evaluated using the Completeness Cytoreduction score[7]. The indication of CLN or PH disease resection was based on the intraoperative findings of suspicious lymph nodes (those measuring more than $1 \mathrm{~cm}$ and/or indurated at palpation) or carcinomatosis in the $\mathrm{PH}$ peritoneum, respectively. We used Aletti Score to quantify the surgical complexity [8] and we evaluated postoperative complications following Clavien-Dindo Classification [9].

The indication of neoadjuvant chemotherapy was based on the sum of procedures required to achieve complete cytoreduction, on medical comorbidities, and on the potential to tolerate an extensive procedure. Patients with deep infiltration of the small bowel mesentery, diffuse carcinomatosis involving large parts of the small bowel, stomach, infiltration of the duodenum or pancreas (not limited to the pancreatic tail), or more than two bowel resections required to eradicate the disease were considered for neoadjuvant chemotherapy. After three 
cycles of platinum and taxane-based chemotherapy, a clinical, biological and imaging evaluation of the response to chemotherapy were performed. In case of poor response or bad performance status, three additional cycles of chemotherapy where administered before the surgery. Adjuvant chemotherapy was administered, when feasible, within 2 months after the surgery with carboplatin and paclitaxel until completing a total of six cycles. In case of poor response with important residual disease, two to three cycles of chemotherapy or antiangiogenic maintenance treatment with bevacizumab were added after discussion at the tumor board. To evaluate the accuracy of an expert radiologist for the detection of CLN involvement, all the preoperative CTs a double lecture by an experienced radiologist of our center (G.B.).

\subsection{Study data}

Medical records were carefully examined, and patient demographic data with particular emphasis on operative records to detail the extent and distribution of the disease spread, surgical procedures, histologic data, and follow-up data were included.

\subsection{Statistical analysis}

Data were summarized by frequency and percentage for categorical variables and by median and range for continuous variables. Comparisons between groups were performed using the Chi-squared or Fisher's exact test for categorical variables and the Mann-Whitney test for continuous variables. Disease-free survival (DFS) was defined as the time from the date of diagnosis until relapse or death, patients alive and disease-free were censored at last follow-up news. Overall survival (OS) was defined as the time from the date of diagnosis until death, patients alive were censored at last follow-up news. Survival data were summarized using the Kaplan-Meier method with their $95 \%$ confidence intervals. Univariable analysis was 
performed using the log-rank test for categorical variable and the Cox model for continuous variable. Multivariable analysis was performed using the Cox model and hazard ratios were estimated with their $95 \%$ confidence intervals (CI). Sensitivity and specificity were estimated with their 95\% CI (Binomial exact). All reported $p$ values were 2-sided. For all the statistical tests, differences were considered significant at 5\% level. Statistical analyses were conducted using STATA 13 (StataCorp, Texas, USA) software.

\section{RESULTS}

During the study period, 150 patients underwent a complete CRS for frontline treatment of advanced epithelial OC. Of them, 43 (28.7\%) underwent CLN resection and 22/43 (51.2\%) also received PH disease resection. Metastatic involvement was identified in 17/43 (39.5\%) patients. There were not significant differences in baseline characteristics between patients with positive and negative CLN, view Table 1.

Table 1. Baseline characteristics of patients with CLN resection.

All patients underwent a pelvic peritonectomy, total hysterectomy, bilateral adnexectomy, total infragastric omentectomy and pelvic and paraaortic lymphadenectomy by laparotomy. A complete cytoreduction was achieved in all of them [7]. Patients with positive CLN had a significantly higher PCI and number of affected anatomic regions. CLN involvement was also significantly associated with high scores of Surgical Complexity Score (SCS) of Aletti, large bowel resection and left diaphragm stripping.

When analyzing the different regions of PCI, even if not significant, we observed a trend toward more extensive disease in the group of patients with positive CLN, with a higher score of upper abdomen PCI and of small bowel PCI, view Table 2.

Table 2. Surgical data of patients with CLN resection. 
174 Positive CLN were significantly associated with PH disease and paraaortic lymph node

175 (PALN) involvement. In the same line, the number of PALN affected was higher in patients 176 with CLN involvement, view Table 3.

177 Table 3. Anatomopathological findings of patients with CLN resection.

178 A significantly higher fluid loss (blood plus ascites) during surgery was observed in the 179 patients with CLN involvement with a median (range) of 2300 (332-6860) ml vs. 1257.5 180 (300-3800) $\mathrm{ml}$ in patients with negative CLN, $p=0.028$. We did not find significant differences in operative time between the patients with positive and negative CLN with a median (range) of 264 (119-522) minutes and 242 (124-432) minutes, respectively; $p=0.502$. In the same line, there were no differences in the length of hospitalization stay in the two groups with a median between the two groups of patients $(7 / 17(41.2 \%)$ in CLN positive vs. $6 / 26(23.1 \%)$ in CLN negative; $p=0.206$ ).

The median overall follow-up was 61.7 months $(95 \% \mathrm{CI}=[44.0-81.4])$. During the study period, $33(76.7 \%)$ out of the 43 patients relapsed, 17/26 (65.4\%) in the group with negative CLN and 16/17 (94.1\%) in the group of positive CLN. Out of the 9 patients with metastatic lung progression, 7 had positive CLN at diagnosis, just as 4 of the 5 patients with metastatic hepatic relapse. Also, CLN were found to be involved in 5 of the 7 women who had mediastinal lymph node progression. Relapse within the 6 months after the end of the The median DFS for all patients was 19.4 months $(95 \% \mathrm{CI}=[13.3-25.8])$. The median DFS in the group of patients with positive and negative CLN were 11.3 months $(95 \% \mathrm{CI}=[8.1-$ 19.4]) and 25.8 months (95\% CI $=[18.5-$ not reached $]$ ), respectively; $p<0.001$. Figure 1 
displays the DFS curves according to the CLN status.

The median OS for all patients was 73.1 months $(95 \% \mathrm{CI}=[37.2-$ not reached $])$. The median OS in the group of patients with positive CLN was 31.6 months $(95 \% \mathrm{CI}=[16.6-80.7])$ and in the group with negative CLN it was not reached $(95 \% \mathrm{CI}=[48.0-$ not reached $]) ; p=0.007$. Figure 1 shows the OS curves according to the CLN status.

Figure 1. Disease-free and overall survivals according to CLN status.

In univariable analysis, we found that age, FIGO stage, neoadjuvant chemotherapy, histologic grade, presence of ascites and small bowel PCI were not associated neither with DFS nor with OS; whereas CLN involvement (HR: 3.79, $\mathrm{p}<0.001$ and 3.13, $\mathrm{p}=0.007$ ), PCI (HR: 1.12, $\mathrm{p}<0.001$ and 1.11, $\mathrm{p}=0.002)$, upper abdomen PCI (HR: 1.34, $\mathrm{p}<0.001$ and 1.35, $\mathrm{p}=0.007)$ and SCS of Aletti (HR: 1.14, $\mathrm{p}=0.027$ and $1.25, p=0.005)$ were significantly associated with DFS and OS, respectively. Confirmed disease at the PH and number of positive PALN were significantly associated with OS and DFS, respectively (Table 4).

Table 4. Univariable disease-free and overall survival analysis

In multivariable analysis, we included clinically relevant variables. Both CLN involvement (HR: 2.66, 95\% CI $=[1.14-6.21], p=0.024)$ and high PCI $(\mathrm{HR}: 1.11,95 \% \mathrm{CI}=[1.03-1.20]$, $p=0.008)$ were independently associated with decreased DFS, whereas number of positive PALN was not $(\mathrm{HR}: 0.97,95 \% \mathrm{CI}=[0.91-1.04], p=0.407)$.

The sensitivity and the specificity of the re-reading of the CT by an expert radiologist in identifying positive CLN were 76.5\% (95\% CI $=[50.1-93.2])$ and $52.0 \%(95 \% \mathrm{CI}=[31.3-$ 72.2]), respectively. In contrast, the sensitivity and the specificity of the non-expert radiologist were $20.0 \%(95 \% \mathrm{CI}=[4.3-48.1])$ and $95.7 \%(95 \% \mathrm{CI}=[78.1-99.9])$, respectively.

Table 5 summarizes the available studies evaluating the role of CLN resection.

Table 5. Available studies assessing the role of CLN resection in patients with advanced epithelial ovarian cancer. 


\section{DISCUSSION}

226

227

228

Residual tumor after CRS is one of the most important prognostic factors of survival of patients with advanced OC[10-12]. Size of residual tumor has been significantly associated with decreased survival[13]. In the upper abdomen, there are some specific disease sites such as the $\mathrm{PH}$, which can preclude a complete cytoreduction[13-18]. In the last decades, the use of extensive UAP in the surgical approach of OC has significantly increased the rate of optimal primary cytoreduction[2,3]. Our team, as well as other workgroups, demonstrated that resection of enlarged CLN and metastatic disease of the PH was both feasible and with an acceptable morbidity[4,19-22]. However, gynecologic surgeons are often not familiar with this kind of surgical procedure as they are uncommonly required in CRS for OC. Moreover, surgery at the $\mathrm{PH}$ requires high level surgical skills as it contains important anatomical structures such as the hepatic artery, the portal vein and the common bile duct. It is possible in these cases to work with an interdisciplinary team in order to achieve complete cytoreduction[20].

\section{Incidence of CLN involvement}

The real incidence of CLN involvement in patients with advanced epithelial OC is unclear and probably underestimated, as systematic hepato-celiac lymphadenectomy is not performed. In fact, CLN resection is only performed in case of suspicious bulky lymph nodes[22]. In our series, CLN resection was performed when intraoperative suspicious CLN were found. The procedure was done in $28.7 \%$ of patients with a complete CRS. Among the patients with CLN resection, $39.5 \%$ had CLN involvement. Hence, our estimated incidence of CLN involvement is $11.3 \%(17 / 150)$. 
In a retrospective study, Rodriguez et al found that patients requiring UAP due to disease spread at this location had higher preoperative disease overall volume when compared to patients that did not require this kind of procedure[23]. We found similar results in our series, as disease extension measured by the PCI and the number of affected regions was significantly associated with CLN involvement. Disease spread to the upper abdomen was also more frequent in the patients with positive CLN, and left diaphragm stripping was performed more frequently. CLN involvement was also associated with confirmed anatomopathological disease in the $\mathrm{PH}$.

CLN involvement was significantly associated with large bowel resection and disease spread to small bowel mesentery. In a series of patients undergoing rectosigmoid resection during primary or interval debulking surgery for advanced OC, Gallotta et al. found mesenteric lymph node involvement in $47 \%$ of patients. Mesenteric lymph node involvement was associated with depth of bowel infiltration and with isolated celiac trunk or aortic lymph node recurrences[24]. Salani et al. studied the same kind of patients and found that mesenteric involvement was correlated with bowel wall involvement and tumor spread to pelvic and PALN[25]. In the same line, another workgroup found invasion of the muscularis propria and retroperitoneal lymph node metastasis significantly correlated with mesenteric lymph node involvement[26]. Even if we did not evaluate mesenteric lymph node involvement, our results also suggest an increased risk of CLN involvement when disease spreads to the bowel or the mesentery. In fact, a longitudinal pattern of ovarian tumor spread from bowel wall lymphatics through mesenteric lymph nodes and, subsequently, to the upper lymph node stations has already been described[27]. Due to the proximity of the nodes at the base of the mesentery and the retroperitoneum, mesenteric lymph nodes metastasis could spread into the 
retroperitoneum and ascend along the paraaortic or aortocaval group[28].

275 On the other hand, CLN involvement was associated with PALN involvement. In fact, in our study, all the patients with positive CLN had PALN involvement. Among the patients with

277

CLN involvement, the $71 \%(12 / 17)$ had more than four positive PALN. Our results are biologically plausible as drainage from paraaortic nodes immediately below the left renal vein to the CLN has been demonstrated[29]. Lymphadenectomy in ovarian neoplasm (LION) randomized trial (NCT00712218) aimed to evaluate the impact on overall survival of systematic lymphadenectomy in patients with OC stage IIB-IV undergoing complete PDS with pre and intraoperatively clinical negative lymph nodes. Results presented at the last ASCO meeting showed that microscopic metastases were present in $56 \%$ of the patients in LNE arm. Despite this finding, there were not significant differences in OS between the two arms[30]. Our results suggest presence of occult lymph node involvement upper to the renal vein and could explain the absence of benefit of systematic lymphadenectomy in these patients.

\section{Prognostic impact of CLN involvement}

In our study, CLN involvement was associated with short-term recurrence and resistance to platin-based chemotherapy. We found a gain of DFS and OS in patients with negative CLN. These results are concordant with our previous study, in which disease in the CLN was associated to decreased survival and resistance to chemotherapy in patients with primary and recurrent $\mathrm{OC}[5]$. Furthermore, CLN involvement was found to be a high-risk marker for metastatic and mediastinal lymph node progression. More than $80 \%$ of patients with hepatic or lung metastasis at recurrent disease had positive CLN.

In multivariable analysis, high PCI and CLN involvement were both independently associated with decreased DFS. Even if residual tumor has a more important prognostic impact than 
initial extent of tumor burden[1], our series showed that in patients with complete cytoreduction, PCI remained an independent risk factor of decreased DFS. These findings are similar to other studies. The survival benefit obtained by an optimal cytoreduction seemed to decrease with increasing initial tumor volume[31]. In a previous study, our workgroup found that complex surgical procedures involving two or more visceral resections, tumor volume an $\mathrm{d}$ extension of the disease before surgery decreased survival rates[32].

Patients with different degree of disease extension to the upper abdomen and patients with positive CLN are both included in stage IIIC of FIGO classification. Other authors have suggested to modify current FIGO staging system[33]. We believe that FIGO stage IIIC should be subdivided depending on criteria like PCI score or CLN status in order to define a subgroup with a poorer prognosis. Due to their poor prognosis, another option would be to consider patients with CLN involvement as a FIGO stage IVB, analogously to patients with cardiophrenic lymphatic involvement, which are currently included in this subgroup stage[34].

Benefit of extensive CRS procedures in CLN positive patients remains unclear. In our study, patients with CLN involvement underwent more complex procedures with higher median Aletti SCS when compared to patients with negative CLN. There were no differences in surgical postoperative complications depending on CLN status, but the overall rate of postoperative major complications was high (13/43 - 30.2\%). Extensive procedures have a non-negligible morbidity and can decrease patient's quality of life[2,35-38].

Patients with CLN involvement have poor prognosis even after complete CRS. Medical personalized strategies with new target therapies may be a way to improve their outcome. It would be interesting to identify these patients preoperatively to tailor the optimal surgical timing and to intensify treatment modalities. We found a good sensitivity (77\%) for the detection of CLN involvement by the double lecture of the CT performed by an expert 
324 radiologist, while the sensitivity of a non-expert radiologist was poor (20\%). The low

325 specificity of the expert radiologist could be explained by the enlargement of the reactive 326 CLN, probably due to tumoral burden.

327 The main limitations of our study are its unicentric retrospective design and the small sample 328 size. However, even if CLN resection is an uncommon procedure in surgical approach of 329 advanced OC, the population of our study is homogeneous as all patients were primary 330 diagnosed of advanced epithelial OC and underwent a complete cytoreduction, which can 331 allow to better assess survival of these patients. Another important strength of this study is the 332 long follow-up of our patients.

\section{CONCLUSION}

CLN involvement and high PCI score are independently associated with a decreased DFS after complete CRS for OC. CLN involvement is a marker of diffuse disease and an independent risk factor for early recurrent disease. Medical personalized strategies with new target therapies may be the best option to improve survival in these patients. These findings should be confirmed in further prospective and multicentric studies. 


\section{REFERENCES}

[1] Eisenkop SM, Spirtos NM, Friedman RL, Lin WCM, Pisani AL, Perticucci S. Relative

influences of tumor volume before surgery and the cytoreductive outcome on survival

[5] Martínez A, Pomel C, Filleron T, De Cuypere M, Mery E, Querleu D, et al. Prognostic relevance of celiac lymph node involvement in ovarian cancer. Int J Gynecol Cancer 2014;24:48-53. doi:10.1097/IGC.0000000000000041.

[6] Sugarbaker PH. Peritonectomy procedures. Ann Surg 1995;221:29-42.

[7] Gilly FN, Cotte E, Brigand C, Monneuse O, Beaujard AC, Freyer G, et al. Quantitative prognostic indices in peritoneal carcinomatosis. Eur J Surg Oncol 2006;32:597-601. doi:10.1016/j.ejso.2006.03.002. 
[8] Aletti GD, Santillan A, Eisenhauer EL, Hu J, Aletti G, Podratz KC, et al. A new frontier for quality of care in gynecologic oncology surgery: Multi-institutional assessment of short-term outcomes for ovarian cancer using a risk-adjusted model. Gynecol Oncol 2007;107:99-106. doi:10.1016/j.ygyno.2007.05.032.

[9] Dindo D, Demartines N, Clavien PA. Classification of surgical complications: A new proposal with evaluation in a cohort of 6336 patients and results of a survey. Ann Surg 2004;240:205-13. doi:10.1097/01.sla.0000133083.54934.ae.

[10] Bristow BRE, Tomacruz RS, Armstrong DK, Trimble EL, Montz FJ. Maximal Cytoreductive Surgery for Advanced Ovarian Carcinoma During the Platinum Era: 2002;20:1248-59. doi:10.1200/JCO.2002.20.5.1248.

[11] Bois A Du, Reuss A, Pujade-Lauraine E, Harter P, Ray-Coquard I, Pfisterer J. Role of surgical outcome as prognostic factor in advanced epithelial ovarian cancer: A combined exploratory analysis of 3 prospectively randomized phase 3 multicenter trials: by the arbeitsgemeinschaft gynaekologische onkologie studiengruppe ovarialkarzin. Cancer 2009;115:1234-44. doi:10.1002/cncr.24149.

[12] Winter WE, Maxwell GL, Tian C, Carlson JW, Ozols RF, Rose PG, et al. Prognostic factors for stage III epithelial ovarian cancer: A Gynecologic Oncology Group study. J Clin Oncol 2007;25:3621-7. doi:10.1200/JCO.2006.10.2517.

[13] Heitz F, Harter P, Alesina PF, Walz MK, Lorenz D, Groeben H, et al. Pattern of and reason for postoperative residual disease in patients with advanced ovarian cancer following upfront radical debulking surgery. Gynecol Oncol 2016;141:264-70. doi:10.1016/j.ygyno.2016.03.015.

[14] Eisenkop SM, Spirtos NM. What are the current surgical objectives, strategies, and technical capabilities of gynecologic oncologists treating advanced epithelial ovarian cancer? Gynecol Oncol 2001;82:489-97. doi:10.1006/gyno.2001.6312. 
[15] Salani R, Axtell A, Gerardi M, Holschneider C, Bristow RE. Limited utility of conventional criteria for predicting unresectable disease in patients with advanced stage epithelial ovarian cancer. Gynecol Oncol 2008;108:271-5. doi:10.1016/j.ygyno.2007.11.004.

[16] Bristow RE, Duska LR, Lambrou NC, Fishman EK, O’Neill MJ, Trimble EL, et al. A model for predicting surgical outcome in patients with advanced ovarian carcinoma using computed tomography. Cancer 2000;89:1532-40.

[17] Axtell AE, Lee MH, Bristow RE, Dowdy SC, Cliby WA, Raman S, et al. Multiinstitutional reciprocal validation study of computed tomography predictors of suboptimal primary cytoreduction in patients with advanced ovarian cancer. J Clin Oncol 2007;25:384-9. doi:10.1200/JCO.2006.07.7800.

[18] Nougaret S, Addley HC, Colombo PE, Fujii S, Al Sharif SS, Tirumani SH, et al. Ovarian Carcinomatosis: How the Radiologist Can Help Plan the Surgical Approach. RadioGraphics 2012;32:1775-800. doi:10.1148/rg.326125511.

[19] Raspagliesi F, Ditto A, Martinelli F, Haeusler E, Lorusso D. Advanced ovarian cancer: Omental bursa, lesser omentum, celiac, portal and triad nodes spread as cause of inaccurate evaluation of residual tumor. Gynecol Oncol 2013;129:92-6. doi:10.1016/j.ygyno.2013.01.024.

[20] Song YJ, Lim MC, Kang S, Seo SS, Kim SH, Han SS, et al. Extended cytoreduction of tumor at the porta hepatis by an interdisciplinary team approach in patients with epithelial ovarian cancer. Gynecol Oncol 2011;121:253-7. doi:10.1016/j.ygyno.2010.12.350.

[21] Tozzi R, Traill Z, Garruto Campanile R, Ferrari F, Soleymani Majd H, Nieuwstad J, et al. Porta hepatis peritonectomy and hepato-celiac lymphadenectomy in patients with stage IIIC-IV ovarian cancer: Diagnostic pathway, surgical technique and outcomes. 
Gynecol Oncol 2016;143:35-9. doi:10.1016/j.ygyno.2016.08.232.

417 [22] Gallotta V, Ferrandina G, Vizzielli G, Conte C, Lucidi A, Costantini B, et al. Hepatoceliac Lymph Node Involvement in Advanced Ovarian Cancer Patients: Prognostic Role and Clinical Considerations. Ann Surg Oncol 2017. doi:10.1245/s10434-017-6005-1.

[23] Rodriguez N, Miller A, Richard SD, Rungruang B, Hamilton CA, Bookman MA, et al. Upper abdominal procedures in advanced stage ovarian or primary peritoneal carcinoma patients with minimal or no gross residual disease: An analysis of Gynecologic Oncology Group (GOG) 182. Gynecol Oncol 2013;130:487-92. doi:10.1016/j.ygyno.2013.06.017.

[24] Gallotta V, Fanfani F, Fagotti A, Chiantera V, Legge F, Alletti SG, et al. Mesenteric lymph node involvement in advanced ovarian cancer patients undergoing rectosigmoid resection: Prognostic role and clinical considerations. Ann Surg Oncol 2014;21:2369_ 75. doi:10.1245/s10434-014-3558-0.

[25] Salani R, Diaz-Montes T, Giuntoli RL, Bristow RE. Surgical management of mesenteric lymph node metastasis in patients undergoing rectosigmoid colectomy for locally advanced ovarian carcinoma. Ann Surg Oncol 2007;14:3552-7. doi:10.1245/s10434-007-9565-7.

[26] Baiocchi G, Cestari LA, MacEdo MP, Oliveira RAR, Fukazawa EM, Faloppa CC, et al. Surgical implications of mesenteric lymph node metastasis from advanced ovarian cancer after bowel resection. J Surg Oncol 2011;104:250-4. doi:10.1002/jso.21940.

[27] O'Hanlan KA, Kargas S, Schreiber M, Burrs D, Mallipeddi P, Longacre T, et al. Ovarian carcinoma metastases to gastrointestinal tract appear to spread like colon carcinoma: Implications for surgical resection. Gynecol Oncol 1995;59:200-6. doi:10.1006/gyno.1995.0008. 
[28] Mcdaniel P, Varma GK, Granfield J. Pictorial Essay Pathways of Nodal Cecum , Ascending CT Demonstration Metastasis in Carcinomas of the Colon, and Transverse Colon : 1993.

[29] Hirai I, Murakami G, Kimura W, Nara T, Dodo Y. Long descending lymphatic pathway from the pancreaticoduodenal region to the para-aortic nodes: its laterality and topographical relationship with the celiac plexus. Okajimas Folia Anat Jpn 2001;77:189-99.

[30] Harter P, Sehouli J, Lorusso D, Reuss A, Vergote I, Marth C. LION: Lymphadenectomy in ovarian neoplasms-A prospective randomized AGO study group led gynecologic cancer intergroup trial. J Clin Oncol [Internet] 2017;35:5500. Available from: http://ascopubs.org/doi/abs/.

[31] Zivanovic O, Sima CS, Iasonos A, Hoskins WJ, Pingle PR, Leitao MMM, et al. The effect of primary cytoreduction on outcomes of patients with FIGO stage IIIC ovarian cancer stratified by the initial tumor burden in the upper abdomen cephalad to the greater omentum. Gynecol Oncol 2010;116:351-7. doi:10.1016/j.ygyno.2009.11.022.

[32] Martinez A, Ngo C, Leblanc E, Gouy S, Luyckx M, Darai E, et al. Surgical Complexity Impact on Survival After Complete Cytoreductive Surgery for Advanced Ovarian Cancer. Ann Surg Oncol 2016;23:2515-21. doi:10.1245/s10434-015-5069-z.

[33] Menczer J. Is there a revision needed of the current FIGO staging system? Acta Obstet Gynecol Scand 2017;96:1159-61. doi:10.1111/aogs.13193.

[34] Prader S, Harter P, Grimm C, Traut A, Waltering KU, Alesina PF, et al. Surgical management of cardiophrenic lymph nodes in patients with advanced ovarian cancer. Gynecol Oncol 2016;141:271-5. doi:10.1016/j.ygyno.2016.03.012.

[35] Rafii A, Stoeckle E, Jean-Laurent M, Ferron G, Morice P, Houvenaeghel G, et al. Multi-center evaluation of post-operative morbidity and mortality after optimal 
cytoreductive surgery for advanced ovarian cancer. PLoS One 2012;7:e39415. doi:10.1371/journal.pone.0039415.

468 [36] Nieuwenhuyzen-de Boer GM, Gerestein CG, Eijkemans MJC, Burger CW, Kooi GS. Nomogram for 30-day morbidity after primary cytoreductive surgery for advanced stage ovarian cancer. Eur J Gynaecol Oncol 2016;37:63-8.

[37] Chi DS, Zivanovic O, Levinson KL, Kolev V, Huh J, Dottino J, et al. The incidence of major complications after the performance of extensive upper abdominal surgical procedures during primary cytoreduction of advanced ovarian, tubal, and peritoneal carcinomas. Gynecol Oncol 2010;119:38-42. doi:10.1016/j.ygyno.2010.05.031.

475 [38] Schulman-Green D, Ercolano E, Dowd M, Schwartz P, Mccorkle R. Quality of life among women after surgery for ovarian cancer. Palliat Support Care 2008;6:239-47. doi:10.1017/S1478951508000497.

478 
1 Figure 1. Disease-free and overall survivals according to celiac lymph node status.
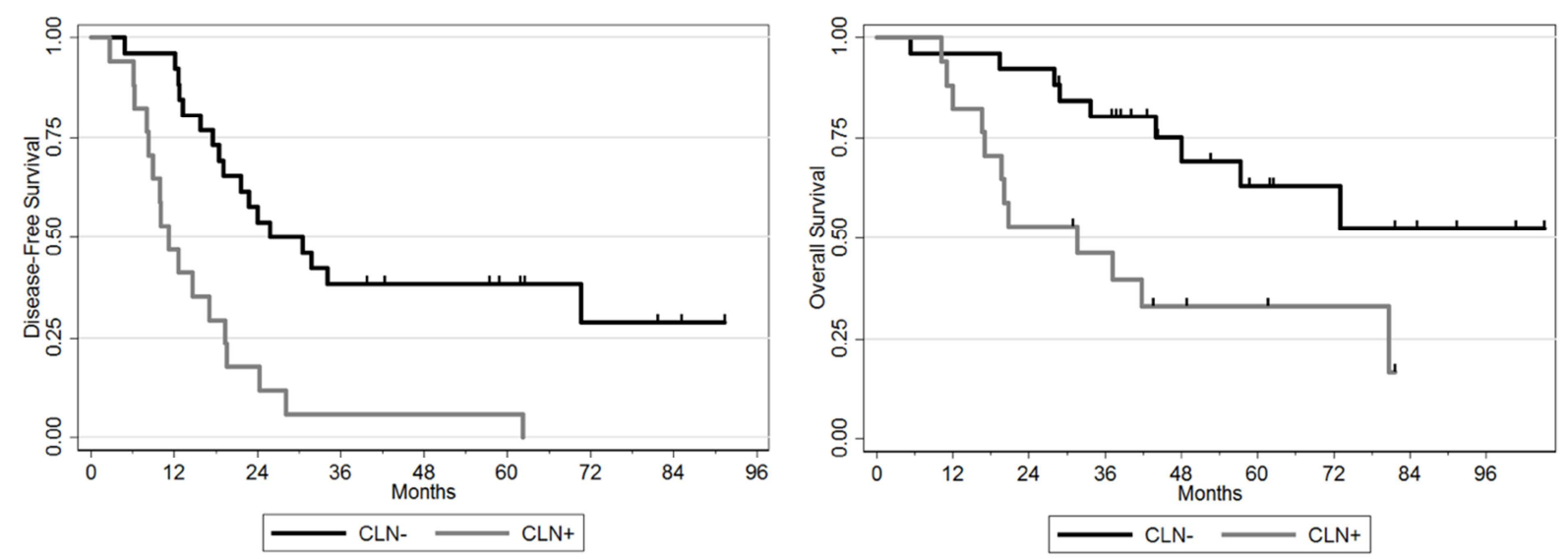
Table 1. Baseline characteristics of patients with celiac lymph node resection.

\begin{tabular}{|c|c|c|c|c|}
\hline & $\begin{array}{c}\text { Overall } \\
n=43\end{array}$ & $\begin{array}{c}\text { Negative CLN } \\
n=26\end{array}$ & $\begin{array}{c}\text { Positive CLN } \\
\mathrm{n}=17\end{array}$ & $\begin{array}{c}p- \\
\text { value }\end{array}$ \\
\hline Age (years) median (range) & $61(22-75)$ & $60(22-74)$ & $65(48-75)$ & 0.115 \\
\hline BMI $\left(\mathbf{k g} / \mathbf{m}^{2}\right)$ median (range) & $\begin{array}{c}23(16.6- \\
37.1)\end{array}$ & $\begin{array}{l}22.9(16.6- \\
33.8)\end{array}$ & $\begin{array}{c}24(18.8- \\
37.1)\end{array}$ & 0.345 \\
\hline \multicolumn{5}{|l|}{$\begin{array}{l}\text { WHO performance status } \\
\text { classification } \mathrm{n}(\%)\end{array}$} \\
\hline 0 & $23(53.5)$ & $15(57.7)$ & $8(47.1)$ & \multirow{2}{*}{0.494} \\
\hline$\geq 1$ & $20(46.5)$ & $11(42.3)$ & $9(52.9)$ & \\
\hline $\begin{array}{l}\text { Preoperative CA-125 }(\mathbf{U I} / \mathbf{m l}) \text { median } \\
\text { (range) } \\
\text { Missing }\end{array}$ & $\begin{array}{l}857(13- \\
15000) \\
7\end{array}$ & $\begin{array}{c}722.5(13- \\
15000) \\
4\end{array}$ & $\begin{array}{l}1365(47- \\
3000) \\
3\end{array}$ & 0.846 \\
\hline \multicolumn{5}{|l|}{ FIGO stage $\mathrm{n}(\%)$} \\
\hline IIIC & $36(83.7)$ & $23(88.5)$ & $13(76.5)$ & \multirow{2}{*}{0.407} \\
\hline IV & $7(16.3)$ & $3(11.5)$ & $4(23.5)$ & \\
\hline
\end{tabular}

CLN: celiac lymph nodes

BMI: body mass index

WHO: World Health Organization

CA-125: cancer antigen 125

FIGO: International Federation of Gynecology and Obstetrics 


\begin{tabular}{|c|c|c|c|c|}
\hline & $\begin{array}{c}\text { Overall } \\
\mathrm{n}=43\end{array}$ & $\begin{array}{l}\text { Negative } \\
\text { CLN } \\
\mathrm{n}=26 \\
\end{array}$ & $\begin{array}{c}\text { Positive CLN } \\
n=17\end{array}$ & $\begin{array}{c}p- \\
\text { value }\end{array}$ \\
\hline \multicolumn{5}{|l|}{ Type of surgery n (\%) } \\
\hline Upfront & $18(41.9)$ & $10(38.5)$ & $8(47.1)$ & \multirow{2}{*}{0.576} \\
\hline Interval & $25(58.1)$ & $16(61.5)$ & $9(52.9)$ & \\
\hline \multicolumn{5}{|l|}{ Intraoperative findings } \\
\hline $\begin{array}{l}\text { PCI median (range) } \\
\text { Missing }\end{array}$ & $\begin{array}{c}22(5-33) \\
2\end{array}$ & $\begin{array}{c}17(5-28) \\
1\end{array}$ & $\begin{array}{c}25.5(10-33) \\
1\end{array}$ & 0.011 \\
\hline $\begin{array}{ll}\text { Upper abdomen PCI } \\
\text { median (range) } \\
\text { Missing }\end{array}$ & $\begin{array}{c}7(0-9) \\
2 \\
\end{array}$ & $\begin{array}{c}6(0-9) \\
1\end{array}$ & $\begin{array}{c}8(2-9) \\
1\end{array}$ & 0.157 \\
\hline $\begin{array}{l}\text { Small bowel PCI median } \\
\text { (range) } \\
\text { Missing }\end{array}$ & $\begin{array}{l}2(0-8) \\
2\end{array}$ & $\begin{array}{c}2(0-7) \\
1\end{array}$ & $\begin{array}{c}3(0-8) \\
1\end{array}$ & 0.098 \\
\hline $\begin{array}{l}\text { No. affected anatomic } \\
\text { regions median (range) } \\
\text { Missing }\end{array}$ & $\begin{array}{c}11(3-13) \\
2\end{array}$ & $\begin{array}{c}10(3-13) \\
1\end{array}$ & $\begin{array}{c}11(7-13) \\
1\end{array}$ & 0.040 \\
\hline \begin{tabular}{ccc|}
$\begin{array}{l}\text { Ascites } \\
\text { (range) }\end{array}$ & $(\mathbf{m l})$ & median \\
\end{tabular} & $200(0-5000)$ & $150(0-4500)$ & $1000(0-5000)$ & 0.087 \\
\hline \multicolumn{5}{|l|}{ Surgical procedures $\mathrm{n}(\%)$} \\
\hline Small bowel resection & $4(9.3)$ & $2(7.7)$ & $2(11.8)$ & 1.000 \\
\hline Large bowel resection & $22(51.2)$ & $9(34.6)$ & $13(76.5)$ & 0.007 \\
\hline $\begin{array}{l}\text { If large bowel resection, } \\
\text { rectosigmoid resection } \\
{[n=22]}\end{array}$ & $18(81.8)$ & $6(66.7)$ & $12(92.3)$ & 0.264 \\
\hline Multiple bowel resection & $6(14)$ & $3(11.5)$ & $3(17.6)$ & 0.666 \\
\hline $\begin{array}{ll}\begin{array}{l}\text { Right } \\
\text { stripping }\end{array} & \text { diaphragm } \\
\end{array}$ & $40(93)$ & $23(88.5)$ & $17(100)$ & 0.266 \\
\hline $\begin{array}{ll}\text { Left } \\
\text { stripping }\end{array}$ & $23(53.5)$ & $10(38.5)$ & $13(76.5)$ & 0.015 \\
\hline $\begin{array}{l}\text { If diaphragm stripping, } \\
\text { diaphragm resection }[\mathrm{n}= \\
40]\end{array}$ & $11(27.5)$ & $7(30.4)$ & $4(23.5)$ & 0.730 \\
\hline Liver resection & $2(4.7)$ & $2(7.7)$ & 0 & 0.510 \\
\hline Cholecystectomy & $17(39.5)$ & $10(38.5)$ & $7(41.2)$ & 0.859 \\
\hline $\begin{array}{ll}\begin{array}{l}\text { Lesser } \\
\text { resection }\end{array} & \text { omentum } \\
\end{array}$ & $33(76.7)$ & $18(69.2)$ & $15(88.2)$ & 0.269 \\
\hline PH resection & $22(51.2)$ & $11(42.3)$ & $11(64.7)$ & 0.151 \\
\hline Splenectomy & $27(62.8)$ & $14(53.8)$ & $13(76.5)$ & 0.133 \\
\hline Distal pancreatectomy & $8(18.6)$ & $5(19.2)$ & $3(17.6)$ & 1.000 \\
\hline Partial gastrectomy & $3(7)$ & $2(7.7)$ & $1(5.9)$ & 1.000 \\
\hline Extended peritonectomy & $37(86)$ & $20(76.9)$ & $17(100)$ & 0.066 \\
\hline Glissonectomy & $6(14)$ & $4(15.4)$ & $2(11.8)$ & 1.000 \\
\hline $\begin{array}{l}\text { Mesentery or bowel } \\
\text { vaporization }\end{array}$ & $13(30.2)$ & $8(30.8)$ & $5(29.4)$ & 0.925 \\
\hline $\begin{array}{l}\text { Partial abdominal wall } \\
\text { resection }\end{array}$ & $7(16.3)$ & $3(11.5)$ & $4(23.5)$ & 0.407 \\
\hline Aletti Score median (range) & $10(4-16)$ & $9(4-14)$ & $12(7-16)$ & 0.011 \\
\hline
\end{tabular}

Table 2. Surgical data of patients with celiac lymph node resection. 
12 CLN: celiac lymph nodes

13 PCI: peritoneal cancer index

14 Upper abdomen PCI: sum of 1 (right upper), 2 (epigastrium) and 3 (left upper) regions score

15 Small bowel PCI: sum of 9 (upper jejunum), 10 (lower jejunum), 11 (upper ileum) and 12 (lower

16 ileum) regions score

17 PH: porta hepatis

18 Extended peritonectomy: peritonectomy of more than three abdominal regions 
Table 3. Anatomopathological findings of patients with celiac lymph node resection.

\begin{tabular}{|c|c|c|c|c|}
\hline & $\begin{array}{c}\text { Overall } \\
n=43\end{array}$ & $\begin{array}{c}\text { Negative } \\
\text { CLN } \\
n=26\end{array}$ & $\begin{array}{c}\text { Positive } \\
\text { CLN } \\
n=17\end{array}$ & $\begin{array}{c}p- \\
\text { value }\end{array}$ \\
\hline \multicolumn{5}{|l|}{ Anatomopathological findings } \\
\hline \multicolumn{5}{|l|}{ Histologic subtype $\mathrm{n}(\%)$} \\
\hline Serous high grade & $33(76.7)$ & $19(73.1)$ & $14(82.4)$ & \multirow{5}{*}{1.000} \\
\hline Serous low grade & $7(16.3)$ & $4(15.4)$ & $3(17.6)$ & \\
\hline Endometrioid & $1(2.3)$ & $1(3.8)$ & 0 & \\
\hline Mixed & $1(2.3)$ & $1(3.8)$ & 0 & \\
\hline $\begin{array}{c}\text { Carcinosarcoma } \\
\end{array}$ & $1(2.3)$ & $1(3.8)$ & 0 & \\
\hline \multicolumn{5}{|l|}{ Chemotherapy Response Score $[\mathrm{n}=25] \mathrm{n}(\%)$} \\
\hline $\begin{array}{l}\text { Type 1: no or minimal } \\
\text { tumor response }\end{array}$ & $10(40 \%)$ & $4(25 \%)$ & $6(66.7 \%)$ & \multirow{4}{*}{0.238} \\
\hline $\begin{array}{l}\text { Type 2: partial tumor } \\
\text { response }\end{array}$ & $10(40 \%)$ & $8(50 \%)$ & $2(22.2 \%)$ & \\
\hline $\begin{array}{l}\text { Type 3: near-complete } \\
\text { tumor response }\end{array}$ & $4(16 \%)$ & $3(18.8 \%)$ & $1(11.1 \%)$ & \\
\hline $\begin{array}{l}\text { Type 3': complete tumor } \\
\text { response }\end{array}$ & $1(4 \%)$ & $1(6.3 \%)$ & 0 & \\
\hline No. CLN removed median (range) & $2(1-6)$ & $2.5(1-6)$ & $2(1-6)$ & \multirow{2}{*}{0.872} \\
\hline No. positive CLN median (range) & $0(0-5)$ & $0(0-0)$ & $1(1-5)$ & \\
\hline PH confirmed disease $\mathrm{n}(\%)$ & $17(39.5)$ & $7(26.9)$ & $10(58.8)$ & $\mathbf{0 . 0 3 7}$ \\
\hline PALN involvement $\mathrm{n}(\%)$ & $31(72.1)$ & $14(53.8)$ & $17(100)$ & 0.002 \\
\hline No. positive PALN median (range) & $3(0-24)$ & $1.5(0-13)$ & $5(1-24)$ & 0.001 \\
\hline$>4$ positive PALN $\mathrm{n}(\%)$ & $19(44.2)$ & $7(26.9)$ & $12(70.6)$ & 0.009 \\
\hline
\end{tabular}

CLN: celiac lymph nodes

Chemotherapy Response Score developed by Böhm et al.

PH: porta hepatis

PALN: paraaortic lymph nodes 
Table 4. Univariable disease-free and overall survival analysis

\begin{tabular}{|l|c|c|c|c|c|c|}
\hline & \multicolumn{3}{|c|}{ Disease-free survival } & \multicolumn{3}{c|}{ Overall survival } \\
\hline & HR & $95 \%$ CI & $p$-value & HR & $95 \%$ CI & $p$-value \\
\hline Age (years) & 1.02 & {$[0.98-1.05]$} & 0.330 & 1.03 & {$[0.98-1.08]$} & 0.200 \\
\hline FIGO stage IV & 0.63 & {$[0.24-1.64]$} & 0.342 & 0.39 & {$[0.09-1.68]$} & 0.189 \\
\hline Neoadjuvant CT & 1.15 & {$[0.58-2.30]$} & 0.687 & 0.98 & {$[0.41-2.36]$} & 0.967 \\
\hline PCI & 1.12 & {$[1.05-1.19]$} & $<\mathbf{0 . 0 0 1}$ & 1.11 & {$[1.04-1.18]$} & $\mathbf{0 . 0 0 2}$ \\
\hline Upper abdomen PCI & 1.34 & {$[1.13-1.58]$} & $<\mathbf{0 . 0 0 1}$ & 1.35 & {$[1.09-1.68]$} & $\mathbf{0 . 0 0 7}$ \\
\hline Small bowel PCI & 1.05 & {$[0.91-1.21]$} & 0.508 & 1.05 & {$[0.89-1.24]$} & 0.564 \\
\hline Ascites (dl) & 1.02 & {$[0.99-1.04]$} & 0.171 & 1.00 & {$[0.97-1.04]$} & 0.930 \\
\hline Aletti Score & 1.14 & {$[1.02-1.29]$} & $\mathbf{0 . 0 2 7}$ & 1.25 & {$[1.07-1.47]$} & $\mathbf{0 . 0 0 5}$ \\
\hline High histologic grade & 0.73 & {$[0.29-1.83]$} & 0.507 & 1.07 & {$[0.29-3.96]$} & 0.919 \\
\hline Positive CLN & 3.79 & {$[1.87-7.69]$} & $<\mathbf{0 . 0 0 1}$ & 3.13 & {$[1.31-7.49]$} & $\mathbf{0 . 0 0 7}$ \\
\hline No. positive PALN & 1.06 & {$[1.01-1.11]$} & $\mathbf{0 . 0 2 7}$ & 1.04 & {$[0.97-1.11]$} & 0.242 \\
\hline PH confirmed disease & 1.93 & {$[0.97-3.83]$} & 0.057 & 2.36 & {$[0.99-5.64]$} & $\mathbf{0 . 0 4 7}$ \\
\hline
\end{tabular}

HR: hazard ratio

FIGO: International Federation of Gynecology and Obstetrics

CT: chemotherapy

PCI: peritoneal cancer index

Upper abdomen PCI: sum of 1 (right upper), 2 (epigastrium) and 3 (left upper) regions score Small bowel PCI: sum of 9 (upper jejunum), 10 (lower jejunum), 11 (upper ileum) and 12 (lower ileum) regions score

CLN: celiac lymph nodes

PALN: paraaortic lymph nodes

$\mathrm{PH}$ : porta hepatis 
Table 5. Available studies assessing the role of CLN resection in patients with advanced epithelial ovarian cancer.

\begin{tabular}{|c|c|c|c|c|c|c|}
\hline $\begin{array}{l}\text { Author and } \\
\text { year }\end{array}$ & $\begin{array}{c}\text { Disease of } \\
\text { included } \\
\text { patients }\end{array}$ & $\begin{array}{c}\text { Number of } \\
\text { patients } \\
\text { included in } \\
\text { the study } \\
\text { n }\end{array}$ & $\begin{array}{c}\text { Number of } \\
\text { patients } \\
\text { with CLN } \\
\text { or PH } \\
\text { disease } \\
\text { resection } \\
\text { n }\end{array}$ & $\begin{array}{c}\text { Number of } \\
\text { patients } \\
\text { with } \\
\text { reported } \\
\text { histopathol } \\
\text { ogical } \\
\text { disease in } \\
\text { CLN or PH } \\
\text { n (\%) } \\
\end{array}$ & $\begin{array}{c}\text { Morbidity } \\
\text { related to } \\
\text { CLN or PH } \\
\text { disease } \\
\text { resection } \\
\text { n }(\%)\end{array}$ & $\begin{array}{c}\text { Prognostic } \\
\text { outcome of } \\
\text { patients } \\
\text { with disease } \\
\text { in CLN or } \\
\text { PH }\end{array}$ \\
\hline $\begin{array}{l}\text { Song et al. } \\
2011\end{array}$ & $\begin{array}{c}\text { Primary and } \\
\text { recurrent } \\
\text { epithelial } \\
\text { ovarian } \\
\text { cancer }\end{array}$ & 155 & $\begin{array}{c}11(\mathrm{PH} \\
\text { disease } \\
\text { resection })\end{array}$ & $\begin{array}{c}11(100) \\
\text { with PH } \\
\text { disease }\end{array}$ & $0(0)$ & $\begin{array}{c}\text { median PFS } \\
8 \text { months } \\
\text { (range 1-13) }\end{array}$ \\
\hline $\begin{array}{l}\text { Martinez et } \\
\text { al. } 2011\end{array}$ & $\begin{array}{c}\text { Primary and } \\
\text { recurrent } \\
\text { epithelial } \\
\text { ovarian } \\
\text { cancer }\end{array}$ & 28 & $\begin{array}{c}28(\mathrm{CLN} \\
\text { and/or PH } \\
\text { disease } \\
\text { resection) }\end{array}$ & $\begin{array}{c}15 / 26(57.7) \\
\text { with CLN } \\
\text { involvement } \\
\\
19 / 28(67.9) \\
\text { with PH } \\
\text { disease }\end{array}$ & $1(3.6)$ & - \\
\hline $\begin{array}{l}\text { Raspagliesi } \\
\text { et al. } 2013\end{array}$ & $\begin{array}{l}\text { FIGO stage } \\
\text { IIIC-IV } \\
\text { epithelial } \\
\text { ovarian } \\
\text { cancer }\end{array}$ & 37 & $\begin{array}{c}5(\mathrm{CLN} \\
\text { resection) } \\
4(\mathrm{PH} \\
\text { disease } \\
\text { resection) }\end{array}$ & $\begin{array}{l}5 \text { (100) with } \\
\text { CLN } \\
\text { involvement } \\
4 \text { (100) with } \\
\text { PH disease }\end{array}$ & $2(5.4)$ & - \\
\hline $\begin{array}{l}\text { Martinez et } \\
\text { al. } 2014\end{array}$ & $\begin{array}{c}\text { Primary and } \\
\text { recurrent } \\
\text { epithelial } \\
\text { ovarian } \\
\text { cancer }\end{array}$ & 41 & $\begin{array}{l}41 \text { (CLN } \\
\text { and/or PH } \\
\text { disease } \\
\text { resection) }\end{array}$ & $\begin{array}{c}23(56.1) \\
\text { with CLN } \\
\text { involvement }\end{array}$ & - & $\begin{array}{c}\text { median PFS } \\
9 \text { months } \\
(95 \% \text { CI [5- } \\
16]) \\
\text { median OS } \\
27 \text { months } \\
(95 \% \text { CI [9- } \\
40])\end{array}$ \\
\hline $\begin{array}{l}\text { Tozzi et al. } \\
2016\end{array}$ & $\begin{array}{c}\text { FIGO stage } \\
\text { IIIC-IV } \\
\text { epithelial } \\
\text { ovarian } \\
\text { cancer }\end{array}$ & 216 & $\begin{array}{c}1 \text { (CLN } \\
\text { and/or PH } \\
\text { disease } \\
\text { resection) }\end{array}$ & $\begin{array}{c}31(100) \\
\text { with PH } \\
\text { disease } \\
\text { and/or CLN } \\
\text { involvement }\end{array}$ & $0(0)$ & 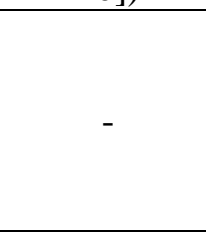 \\
\hline $\begin{array}{l}\text { Gallotta et } \\
\text { al. } 2017\end{array}$ & $\begin{array}{l}\text { FIGO stage } \\
\text { IIIC-IV } \\
\text { epithelial } \\
\text { ovarian } \\
\text { cancer }\end{array}$ & 85 & $\begin{array}{l}85 \text { (CLN } \\
\text { resection) }\end{array}$ & $\begin{array}{l}45(52.9 \%) \\
\text { with CLN } \\
\text { involvement }\end{array}$ & $0(0)$ & $\begin{array}{c}\text { median PFS } \\
16 \text { months } \\
(95 \% \text { CI } \\
[12-19]) \\
\text { median OS } \\
43 \text { months } \\
(95 \% \text { CI } \\
\text { [32-54]) }\end{array}$ \\
\hline
\end{tabular}




\begin{tabular}{|c|c|c|c|c|c|c|}
\hline $\begin{array}{l}\text { Angeles et } \\
\text { al. } 2019\end{array}$ & $\begin{array}{l}\text { FIGO stage } \\
\text { IIIC-IV } \\
\text { epithelial } \\
\text { ovarian } \\
\text { cancer }\end{array}$ & 43 & $\begin{array}{l}43 \text { (CLN } \\
\text { resection) }\end{array}$ & $17(39.5)$ & $0(0)$ & $\begin{array}{c}\text { median DFS } \\
11 \text { months } \\
(95 \% \text { CI [8- } \\
19]) \\
\text { median OS } \\
32 \text { months } \\
\text { (95\% CI } \\
[17-81])\end{array}$ \\
\hline
\end{tabular}

44 CLN: celiac lymph node involvement

45 PH: porta hepatis

46 PFS: progression-free survival

47 CI: confidence interval

48 OS: overall survival

49 DFS: disease-free survival 